\title{
Laser CVD vs. Hot Wall CVD: Coating of Fibres for Ceramic Composites
}

\author{
V. Hopfe, K. Brennfleck*, R. Weiß*, R. Meistring**, K. Schönfeld, R. Jäckel, G. Dietrich** and \\ R. Goller** \\ Fraunhofer-Institut für Werkstoffphysik und Schichttechnologie (IWS), PF 16, 01171 Dresden, Germany \\ * Schunk Kohlenstofftechnik GmbH, PF 100951, 35339 Giessen, Germany \\ ** Daimler-Benz AG (former. Deutsche Aerospace AG), Zentrales Werkstofflabor, 81663 Munich, \\ Germany
}

\begin{abstract}
Based on a technological $5 \mathrm{~kW} \mathrm{cw}-\mathrm{CO}_{2}$ laser, an atmospheric pressure laser assisted CVD process has been established which performs a continuous high rate coating of carbon fibre rovings. Layers of pyrolytic carbon have been deposited from $\mathrm{CH}_{4}$ with a rate of $0.6 \mu \mathrm{m} / \mathrm{s}$ which enhances the tensile strength and Weibull modulus of fibres. In another variant, pyro-C layers have been deposited in a technological thermal hot-wall CVD reactor on fabrics and on preforms. The layer thickness is uniform over the cross section of the fibre bundles, but variations in flow direction have been detected. Composite materials with $\mathrm{SiC}$ matrix have been processed by both liquid precursor infiltration using Si-polymers and by converting a carboneous matrix being infiltrated with liquid silicon. Preforms with uncoated and coated fibres have been infiltrated. The resulting composites are characterized by high tensile strength and crack resistance due to the favourable pull-out behaviour of coated fibres.
\end{abstract}

\section{INTRODUCTION}

Fibre reinforced ceramic composites (CMC) are beeing advanced materials increasingly accepted for high temperature applications. Due to their potential for high strength and stiffness, excellent toughness and low density they are perspective materials e.g. for hot gas turbines, heat exchangers, and break systems for high speed trains. Although the overall mechanical properties of a CMC are governed by the properties of the reinforcement and the matrix materials, processing conditions, and the fibre-matrix interfacial shear stress, the toughness is extremly dependent on the interface between fibres and matrix which can be engineered by coatings. The interfacial layer must meet complex demands among them the protection of fibres from chemical and mechanical interactions during material processing and within their life-cycle, and the optimization of fibre/matrix bonding to achieve high damage tolerance by controlled fibre pullout. For high temperature applications of carbon-carbon ( $\mathrm{SiC}$ ) composites, several complex oxidation protection systems are in advance: (i) deposition of thin ceramic layers (e.g. SiC, h-BN) on the fibre bundles or the fibre woven structures (preforms), (ii) modification of the matrix (e.g. by silicon infiltration), (iii) final encapsulation of the composite material by a multilayer system.

It is the aim of this paper to develop and compare different CVD methods for coating fibre bundles or preforms and to evaluate the mechanical properties of the fibres as well as those of the processed composites. Recently a laser driven CVD (LCVD) method has been introduced for coating carbon fibres and the principle has been demonstrated by depositing refractory materials (e.g. $\left.\operatorname{TiC}_{\mathrm{x}}, \mathrm{TiN}_{\mathrm{x}}, \mathrm{TiB}_{2}, \mathrm{~B}, \mathrm{SiC}\right)$ with a laboratory scale apparatus $/ 1,2 /$. In comparison with the well established hot-wall thermal CVD, the LCVD method is characterized by several significant advantages, among them high deposition rates of typically $0.2 . .2 .0 \mu \mathrm{m} / \mathrm{s}$, small volume cold-wall reactors, thermal reaction paths supported by photo- 
chemical reaction channels, almost no restrictions on deposition temperature and materials to be deposited.

The first part of this paper summarizes the current status of the LCVD method being scaled-up just to the prototype demonstrator level. In the second part, the coating of preforms in an industrial scale CVD reactor will be discussed as an alternative method. The final part of this paper gives an outline of the processing of composites by liquid precursor infiltration of carboneous or $\mathrm{Si}$-polymers followed by a multistep pyrolysis procedure and subsequent liquid silicon infiltration in case of a pure $\mathrm{C}$ matrix. Preforms with uncoated and coated fibres have been infiltrated.

\section{LASER CVD: CONTINUOUS COATING OF ROVINGS}

An atmospheric pressure laser assisted CVD process (AP-LCVD) has been established which performs a continuous high rate coating of rovings. The AP-LCVD process is based on a technological $5 \mathrm{~kW}$ $\mathrm{CW}-\mathrm{CO}_{2}$ laser (Rofin-Sinar, $\mathrm{RS} 850$ ). The system is equipped with a special apparatus for moving and continuously spreading the roving of typically 12000 filaments into a flat fiber tape (width $30 \mathrm{~mm}$ ) prior to deposition. The computer controlled gas delivery system is designed for depositing the carbides, nitrides and borides of $\mathrm{Si}, \mathrm{Ti}$ and $\mathrm{B}$ as well as of other systems with volatile precursors. The scheme of the vertical LCVD reactor is sketched in Fig. 1.

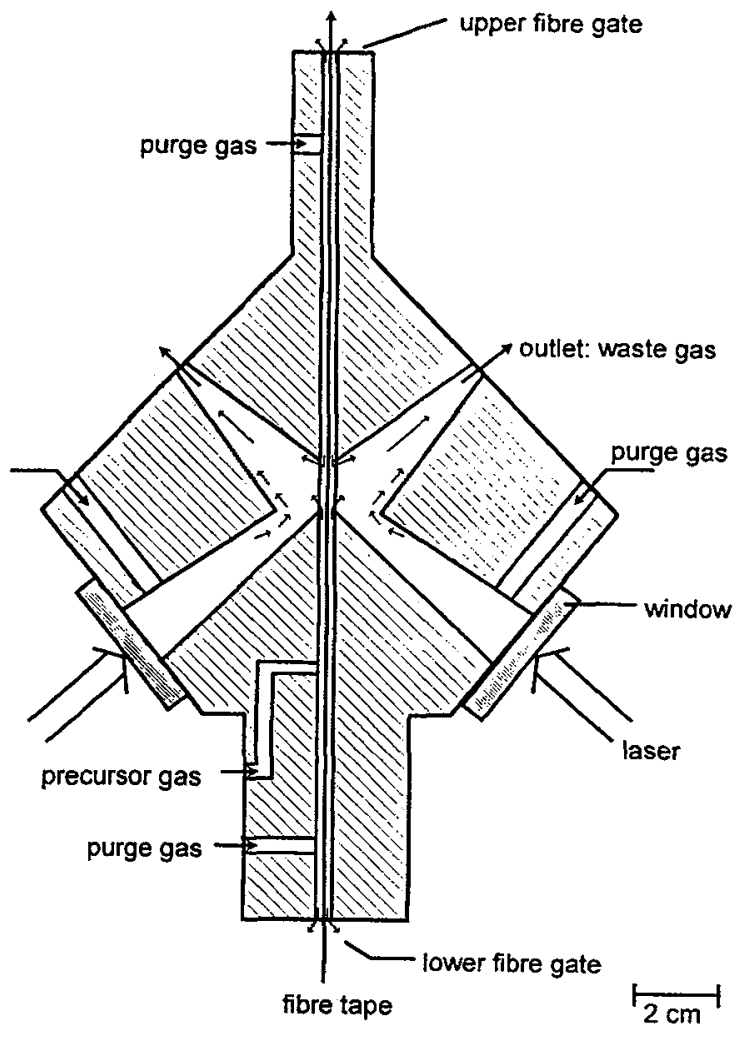

Figure 1: Scheme of the AP laser CVD reactor.
The laser beam is splitted into two equal parts which are formed into beams with rectangular cross section (width: $40 \mathrm{~mm}$, heights: variable $1 . . .4 \mathrm{~mm}$, to adjust power density) before entering the LCVD reactor through two $\mathrm{ZnSe}$ windows being continuously purged $\left(\mathrm{N}_{2}, \mathrm{H}_{2}\right)$ to prevent any deposition of absorbing constituents. The precursor gas is fed-in co-axially with the fibre tape from the bottom of the reactor. After passing the reaction zone the reaction products (waste gas) leave the reactor on top through specially designed channels which will be heated by trapping the transmitted radiation to prevent condensation of pro- ducts with low volatibility. The waste gas is neutralized by an automatically operating burner / scrubber system. The APLCVD reactor is "sealed" against the surrounding atmosphere by two inert gas purged flat channels which forms the gates for passing the endless fibre bundle through the reaction zone.

The reactor is equipped with in-situ diagnostics for controlling operational parameters: twowavelength pyrometry and thermocouples for measuring the temperature in the laser heated area and the chamber respectively, FTIR spectroscopy for continuously measuring the decomposition rate of the precursor and the composition of the gaseous reaction products, pressure gauges for controlling the difference pressure of both the fibre gates and the reaction chamber against the ambient. 
The design of the LCVD reactor and the optimization of its operational conditions have been supported by computational fluid dynamics techniques. Using a commercially available software package (PHOENICS, CHAM Ltd.) the gas flow dynamics and heat transfer in the reaction chamber have been calculated. As an example, the lateral distribution of the flow velocities and isotherms near the laser heated fibre bundle is given in Fig. 2 and 3. Using parameters which are typical for the deposition reactions given below, the precursor forms a free standing laminar gas flow symmetrical to the fibre tape (Fig. 2a). The character of this flow is rather insensitive against changes of the flow rate. Even a ten-fold increase of the rate gives a similiar streamline map near the surface to be deposited but results in some recirculation at the interface between precursor and purge flow (Fig. 2b).

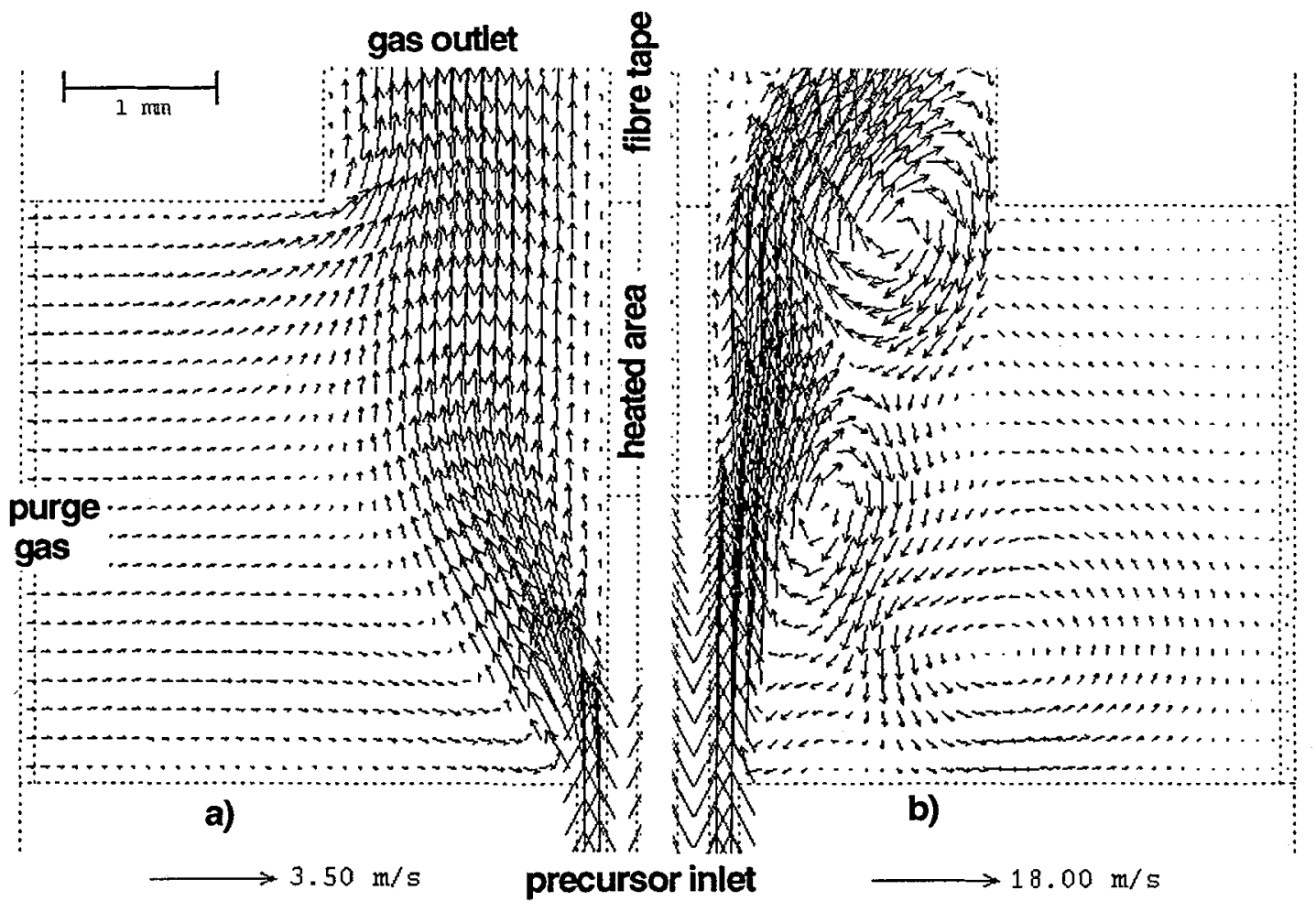

Figure 2: Computational fluid dynamics of the AP-LCVD reactor: flow velocity distribution (a) precursor $\mathrm{CH}_{4}=1.1 \mathrm{slm}$, purge gas $\mathrm{N}_{2}=2 \mathrm{slm}$, temperature of irradiated area $\mathrm{T}=1750 \mathrm{~K}$ (left), (b) $\mathrm{CH}_{4}=11 \mathrm{slm}, \mathrm{N}_{2}=2 \mathrm{slm}, \mathrm{T}=1750 \mathrm{~K}$ (right).

Thus the precursor stream well shields the reaction zone from the purge gas streams. Due to the thermal volume expansion and the increasing viscosity of gases with temperature, a bulging of the streamlines within the hot region has been found, This can be lowered by enhancing the volume rate of precursor gas and purge gas, which increases deposition rate, but decreases the conversion rate of precursor (see below). The temperature gradient near the fibre surface has been estimated as $1.6^{*} 10^{3} \mathrm{~K} / \mathrm{mm}\left(4.5^{*} 10^{3}\right.$ $\mathrm{K} / \mathrm{mm}$ at ten-fold precursor rate) which means that pyrolysis reactions are restricted to a gas layer of several hundred microns above the fibre surface being typical for cold wall reactors. Calculations of species distributions are currently being carried out. 

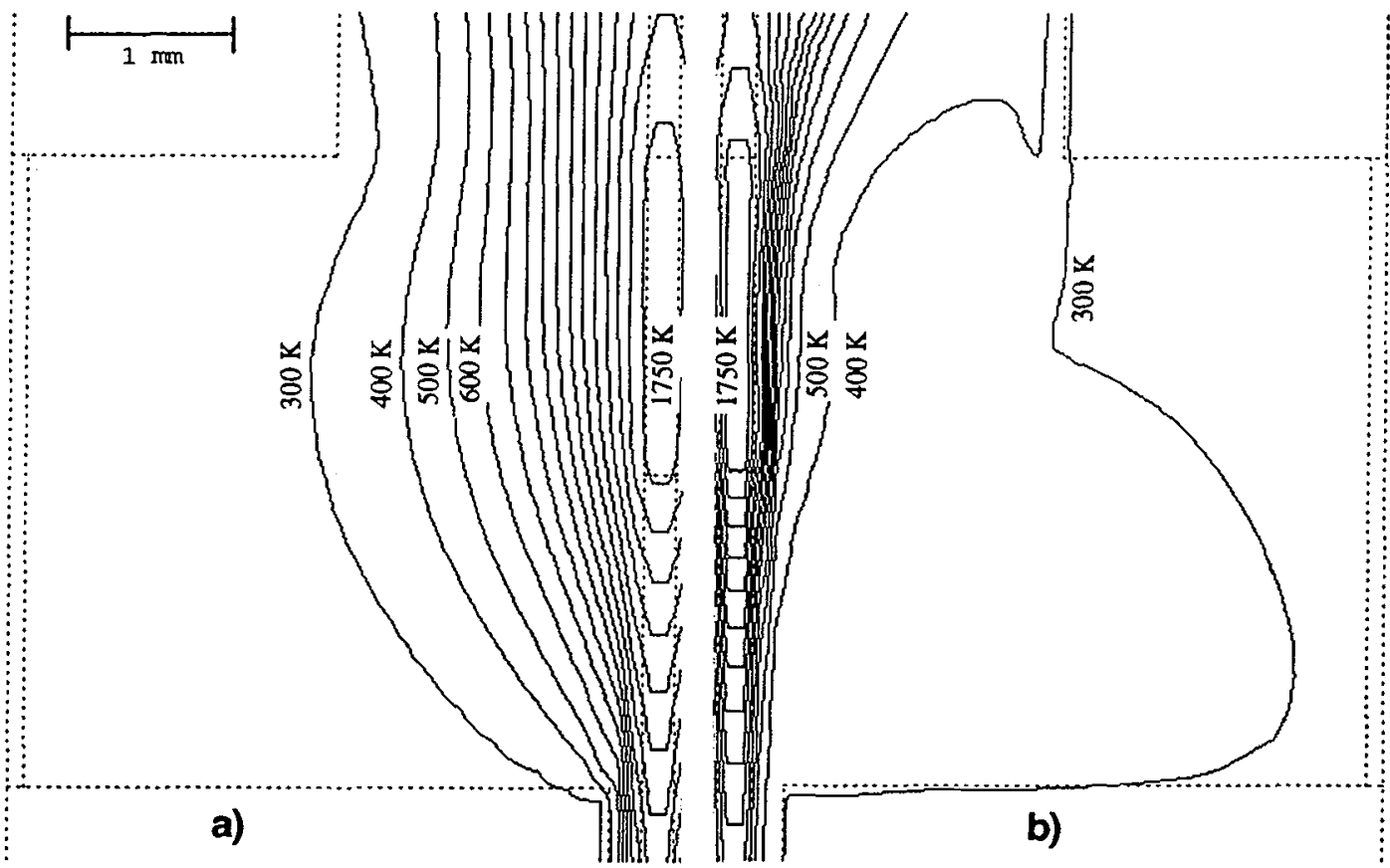

Figure 3: Computational fluid dynamics of the AP-LCVD reactor: temperature distribution (parameters, see Fig. 2).

Depositions have been carried out at high tensile carbon fibre rovings (Hercules AS4C/12k and Toray T800/6k, unsized/untwisted material) using $\mathrm{CH}_{4}$ or $\mathrm{C}_{2} \mathrm{H}_{2}$ as precursors and $\mathrm{H}_{2}$ or $\mathrm{N}_{2}$ as carrier and purge gas, respectively. Homogeneous, very smooth layers have been deposited at $1700 \mathrm{~K} . .2000 \mathrm{~K}$ (laser power $1 \mathrm{~kW} . .2 \mathrm{~kW}$ ) using pure methane as precursor, see Fig. 4. The deposition rate has been estimated as $0.6 \mu \mathrm{m} / \mathrm{s}$. A fibre velocity of $60 \mathrm{~m} / \mathrm{h}$ results in layer thickness of typically $50 \mathrm{~nm}$ (gravimetrically determined), see Fig. 4a. At lower fibre velocity, smooth layers of thickness around $1 \mu \mathrm{m}$ have been deposited (Fig. 4b), which are highly graphitic and textured. During the pyro-C deposition from $\mathrm{CH}_{4}$, the composition of the reaction products have been analysed by FTIR spectroscopy. In addition to the nonreacted precursor only $\mathrm{C}_{2} \mathrm{H}_{2}$ has been detected. The decomposition rate, estimated as about $10 \%$, and the concentration of $\mathrm{C}_{2} \mathrm{H}_{2}$ are nearly independent of laser power, which indicates a mass-flow controlled mechanism.

The RT mechanical properties of the as-received, laser irradiated, and coated fibre bundles have been determined by the roving tensile testing method. The AS4C roving shows no significant variations in both tensile strength and failure intervall. At the T800 fibre an increase of the tensile strength was detected which goes from $2.9 \mathrm{GPa}$ (as-received) to $3.4 \mathrm{GPa}$ (pyro-C, $50 \mathrm{~nm}$ ). Simultaneously the Weibull modulus slightly increases from 7 to 8 . The reinforcement capabilities of the LCVD coated fibres are currently being investigated. 

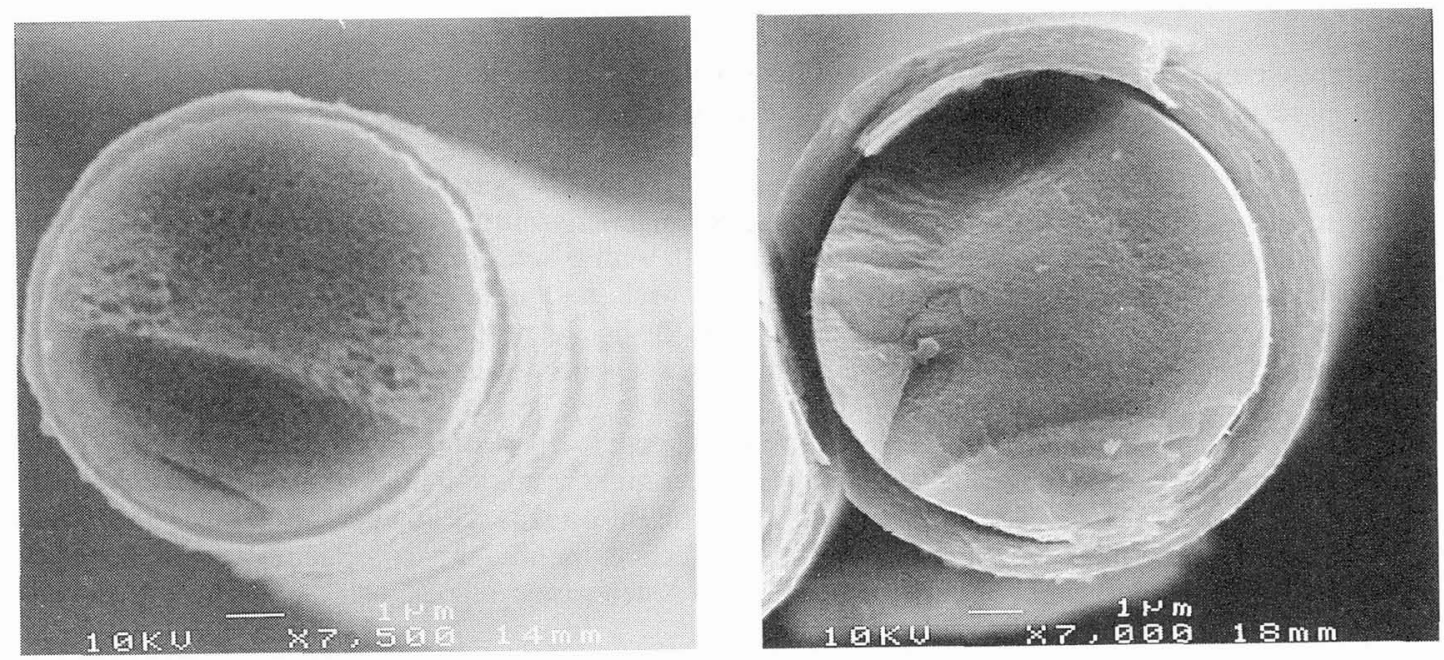

Figure 4: SEM of pyro-C layers on AS4C fibres, (a) thin layer, etched, see text, (b) thick layer.

\section{HOT-WALL CVD: COATING OF PREFORMS IN A BATCH PROCESS}

For comparison pyro-C layers have been deposited on different carbon fibre rovings (Tenax HTA-7, Toray T800), carbon cloth and preforms by a conventional CVD technique. All experiments and investigations were performed in an industrial vertical hot wall reactor with of $0.65 \mathrm{~m}$ diameter and $0.9 \mathrm{~m}$ length and a vertical experimental reactor of $0.35 \mathrm{~m}$ diameter and $0.45 \mathrm{~m}$ length. Feed gas for the pyro-C was $\mathrm{CH}_{4}$ with deposition parameters: total pressure $<10 \mathrm{mbar}$ and deposition temperature $1420 \mathrm{~K}$.

A prerequisite for the preparation of carbon composites with reproducable properties is the homogeneity of the infiltration of the fibre bundles, carbon cloths and prepregs. Therefore the distribution of the layer thickness was analysed at a carbon cloth with $0.8 \mathrm{~m}$ length and $0.48 \mathrm{~m}$ width, see Fig. 5 . The layer

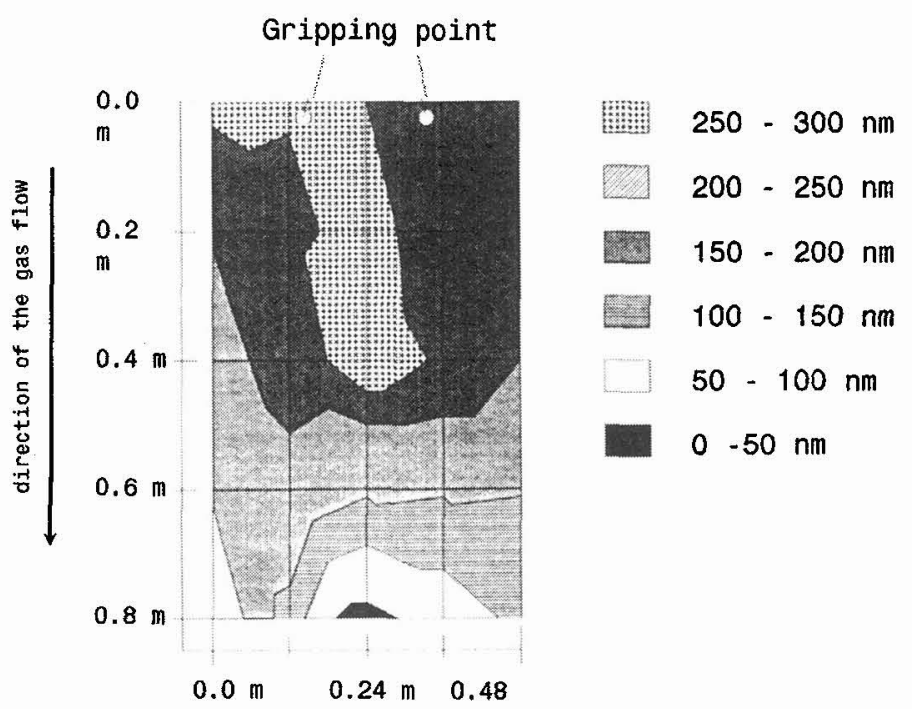

Figure 5: Distribution of pyro-C-layer thickness on a carbon cloth (Tenax/HTA-7) along the deposition zone. 
thickness was measured by SEM. At thin layers $(<100 \mathrm{~nm})$ the measurement of the layer thickness has been improved by treating the pyro- $\mathrm{C}$ coated fiber with air at $830 \mathrm{~K}$ for $15 \mathrm{~min}$. Because of differential oxidation resistance of coating and fiber the contours of the coating can be seen more clearly.

Along the deposition zone the pyro- $\mathrm{C}$ layer thickness on the $\mathrm{C}$-fibers decreases because of depletion effects of the methane concentration, whereas the homogeneity of the layer thickness within the fiber bundle is quite good. As a consequence a carbon cloth with $0.8 \mathrm{~m}$ length and $0.48 \mathrm{~m}$ width has to be turned upside down before second infiltration. Otherwise the length has to be limited to $0.4 \mathrm{~m}$. The width can be expanded to several meters depending on the design of the mounting. This second solution was favoured for practical reasons for the preparation of layers between $50 \mathrm{~nm}-500 \mathrm{~nm}$.

It is known that the homogeneity of the infiltration increases with decreasing temperature whereas the deposition rate decreases exponentially. Too high temperatures result in inhomogeneous deposition. Owing to the extended surface of preforms the deposition rate decreases considerably along the reaction chamber, resulting in thick coatings with bridging effects at the initial part of the deposition zone and nearly no deposition at the end of the deposition zone. A decrease of the deposition temperature considerably improves the homogeneity of the infiltration.

\section{COMPOSITE PROCESSING BY LIQUID PRECURSOR INFILTRATION}

Composite materials with SiC matrix have been processed by both liquid precursor infiltration using Sipolymers and by partial converting a carbonous matrix infiltrated with liquid silicon. Preforms with uncoated / coated fibres have been infiltrated.

Investigations were performed to determine the mechanical strength of $\mathrm{C} / \mathrm{SiC}$ composites depending on fibre coatings and fibre thickness. For this purpose, 3D-carbon fibre preforms were coated with pyro-C by a hot wall CVD process (see, Ch. 3) with variation of the coating thickness between 40 and $145 \mathrm{~nm}$. The densification process consisted of several impregnation and pyrolysis steps using a Si-polymere (polyvinylsilane). The resulting mechanical strengths (bending strength, interlaminar shear strength) were measured after each impregnation/pyrolysis cycle and were compared with those of samples with uncoated fibres. As a result the strength of coated fibre composites is more than 10 times higher compared to that of uncoated fibre composites, see Fig. 6 and 7. The favorable coating thickness is $80-100$ nm.

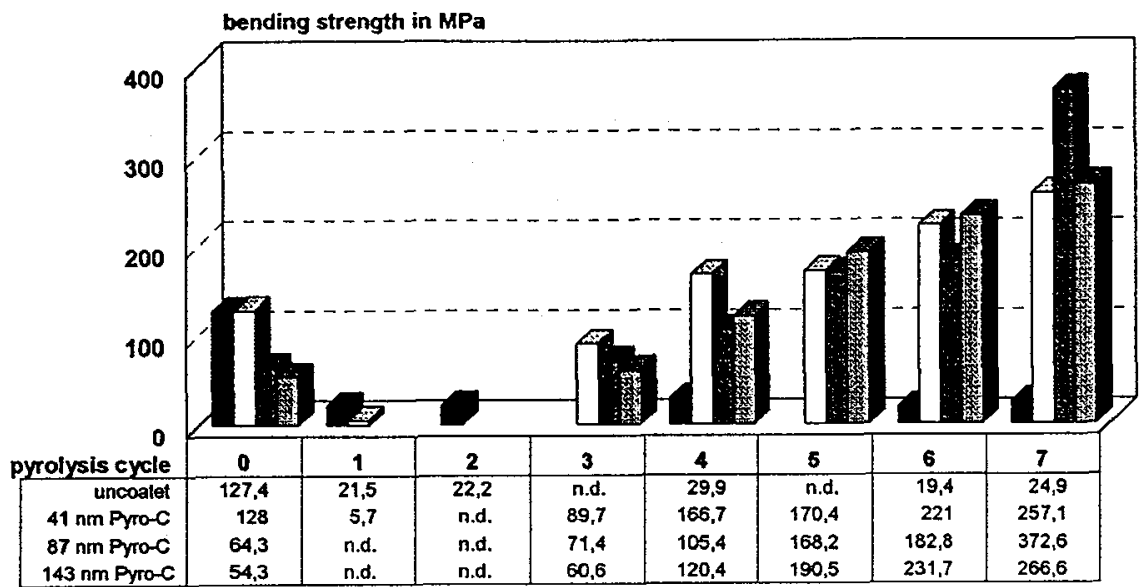

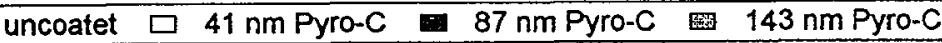

Figure 6: Bending strength of $\mathrm{C} / \mathrm{SiC}$ composites with as-received and pyro- $\mathrm{C}$ coated carbon fibres in dependance of the number of pyrolysis cycles. 


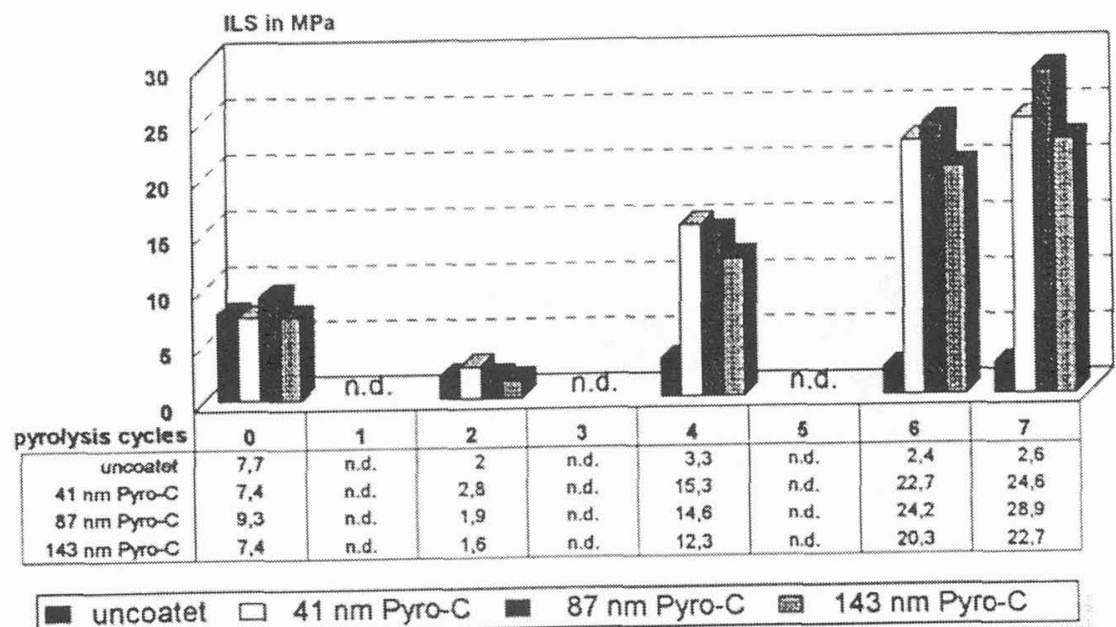

Figure 7: Interlaminar shear strength of $\mathrm{C} / \mathrm{SiC}$ composites with as-received and pyro-C coated carbon fibres in dependance of the number of pyrolysis cycles.

These investigations indicate the essential influence of fibre coatings on the strength and fracture toughness of ceramic matrix composites. The fracture face of composites with coated and uncoated fibres clearly shows pull-out effects of the coated fibres (Fig. 8).
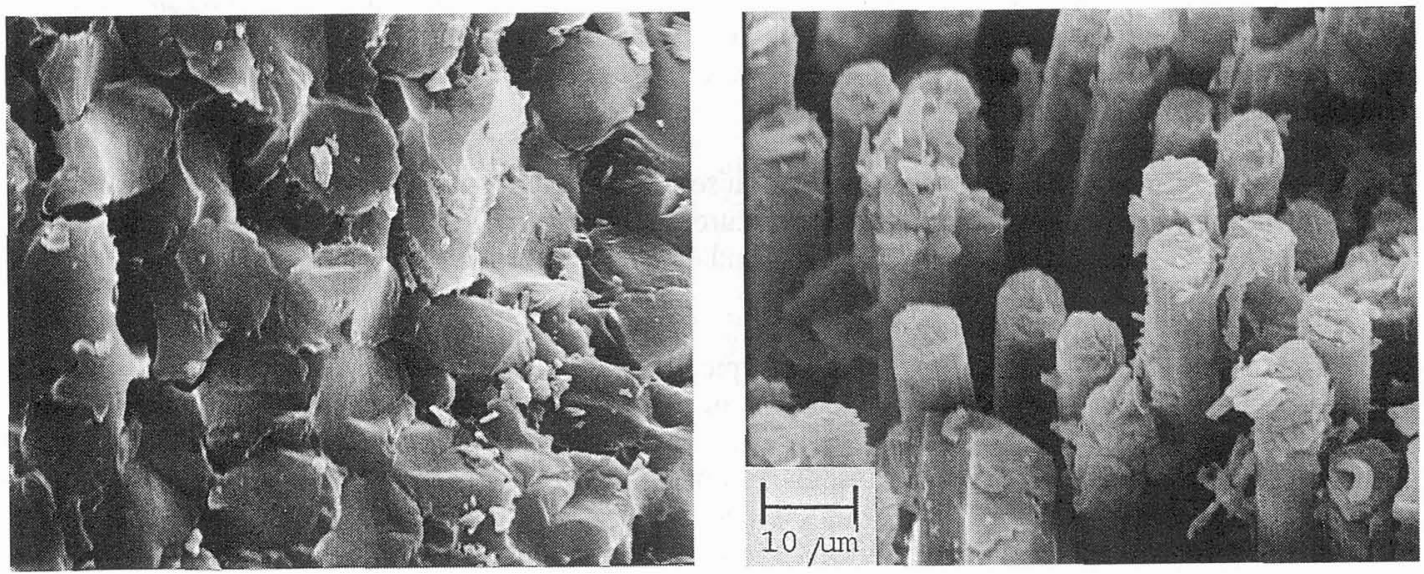

Figure 8: $\mathrm{SEM}$ of fracture face $\mathrm{C} / \mathrm{SiC}$ composite with uncoated fibres (left) and pyro-C coated fibres (right).

To optimize the liquid silicon infiltration process investigations have been carried out to find out useful coating material and coating thicknesses in order to prevent fibre degradation with molten silicon (by converting to $\mathrm{SiC}$ ). Therefore carbon fibres were coated by both pyro-C and $\mathrm{BN}$ using a conventional CVD process by varying the coating thicknesses between 50 and $500 \mathrm{~nm}$. The silicification processes on coated fibre bundles (T800/6k) were carried out at temperatures from $1720 \mathrm{~K}$ to $1970 \mathrm{~K}$ and times 
from 10 to $30 \mathrm{~min}$. Even at low temperatures and short infiltration times the pyro-C layers and the carbon fibres were converted to $\mathrm{SiC}$, see Fig. 9. These results indicate that pyro-C coatings up to $500 \mathrm{~nm}$ cannot protect the carbon fibres and prevent a strong fibre-matrix bonding during the silicification process.

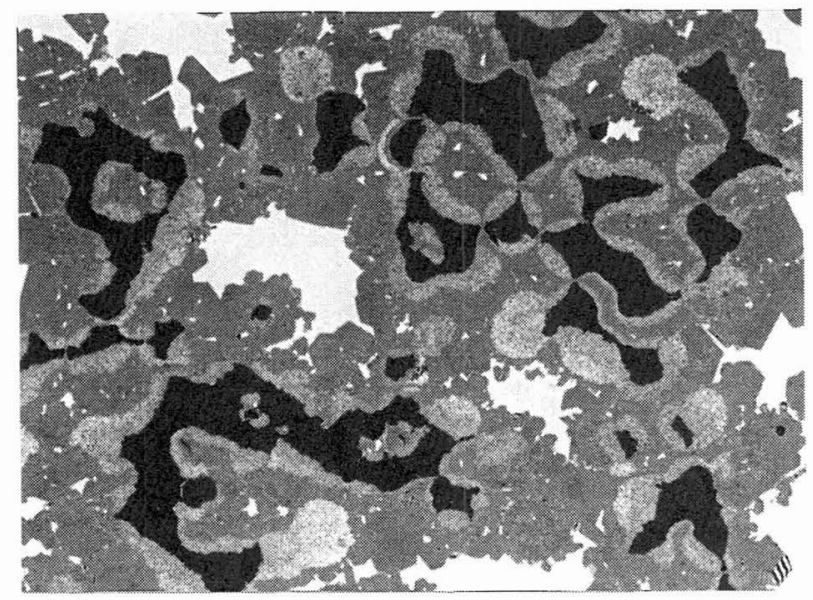

Figure 9: SEM of polished cross section of a silicon infiltrated T800 fibre bundle with a pyro-C coating $(600 \mathrm{~nm})$, white areas indicate formation of $\mathrm{SiC}$ (temperature: $1720 \mathrm{~K}$, time: $30 \mathrm{~min}$ ).

More favorable results have been maintained by BN coatings. Coated fibres will not be wetted by liquid silicon and therefore no attack by chemical interaction can occure. On the other hand the liquid infiltration process is strongly affected by the poor wettability of the BN-coated fibres by liquid silicon. Running investigations have to identify feasible infiltration mechanisms for $\mathrm{BN}$ coated fibre preforms or $\mathrm{C} / \mathrm{C}$ composites.

The investigations revealed another problem. Because of thermal mismatch between $\mathrm{BN}$ coating and carbon fibre, the coating peeled off at high temperatures. To prevent this effect, optimizations are underway, including the variation of coating thickness and deposition temperature.

\section{CONCLUSION}

Compared to the deposition rate of AP-LCVD (typically $0.2 \ldots .2 .0 \mu / \mathrm{s}$ ), the deposition rate of hot wall thermal CVD $(10 \ldots . .100 \mathrm{~nm} / \mathrm{h})$ is some orders of magnitude lower in case of fibre coating of preforms. However this disadvantage is partially compensated by the total surface being coated simultaneously. Further considerations on performance of both CVD methods are underway. They include investigations of coating quality with respect to the desired application of the composites as well as technical (scale-up capability) and economic factors. As a main advantage of the LCVD method, its flexibility is favourably utilized for developing coated fibres for high temperature applications.

\section{Acknowledgement}

The project is funded by the Bundesminister für Forschung und Technologie under contract no. 03M1057D7 within the German materials research programme.

\section{REFERENCES}

11/ Hopfe V., Tehel A., Baier A., Scharsig J., Appl. Surf. Sci. 54 (1992) 78-83.

12/ Hopfe V., Böhm S., Wieghardt G., Schulze A., Appl. Surf. Sci. 69 (1993) 380-387.

13/ Kehr D., Brennfleck K., Weiß R., High Temperatures-High Pressures 22 (1994) 693-707.

14I Langlais F., Prebende C., Proc. 11th Int. Conf. on CVD 1990, 686-695.

15/ Besmann T. M., Johnson M. L., Proc. Third Int. Conf. on Ceramic Materials and Components for Engines, Las Vegas, Nevada USA, Nov. 27 - 30 (1988) 443 - 456. 